\title{
Uncoupling of the Membrane Skeleton from the Lipid Bilayer The Cause of Accelerated Phospholipid Flip-fiop Leading to an Enhanced Procoagulant Activity of Sickled Cells
}

\author{
P. F. H. Franck, E. M. Bevers, B. H. Lubin, P. Comfurius, D. T.-Y. Chiu, J. A. F. Op den Kamp, R. F. A. Zwaal, \\ L. L. M. van Deenen, and B. Roelofsen \\ Department of Biochemistry, State University of Utrecht, Padualaan 8, NL-3584 CH Utrecht, The Netherlands; Department of \\ Biochemistry, Biomedical Center, University of Limburg, NL-6200 MD Maastricht, The Netherlands; Bruce Lyon Memorial \\ Research Laboratory and Department of Hematology/Oncology, Children's Hospital Medical Center of \\ Northern California, Oakland, California 94609
}

\begin{abstract}
We have previously reported that the normal membrane phospholipid organization is altered in sickled erythrocytes. More recently, we presented evidence of enhanced transbilayer movement of phosphatidylcholine $(\mathrm{PC})$ in deoxygenated reversibly sickled cells (RSC) and put forward the hypothesis that these abnormalities in phospholipid organization are confined to the characteristic protrusions of these cells. To test this hypothesis, we studied the free spicules released from RSC by repeated sickling and unsickling as well as the remnant despiculated cells.
\end{abstract}

The rate of transbilayer movement of $P C$ in the membrane of deoxygenated remnant despiculated cells was determined by following the fate of ${ }^{14} \mathrm{C}$-labeled $\mathrm{PC}$, previously introduced into the outer monolayer under fully oxygenated conditions using a PC-specific phospholipid exchange protein from beef liver. The rate of transbilayer movement of PC in the remnant despiculated cells was significantly slower than in deoxygenated native RSC and was not very much different from that in oxygenated native RSC or irreversibly sickled cells. The free spicules had the same lipid composition as the native cell, but were deficient in spectrin. These spicules markedly enhanced the rate of thrombin formation in the presence of purified prothrombinase (Factor $\mathrm{Xa}$, Factor $\mathrm{Va}$, and $\mathrm{Ca}^{2+}$ ) and prothrombin, indicating the exposure of a significant fraction of phosphatidylserine (PS) in the outer monolayer. This effect was not observed when the spicules in this assay were replaced by normal erythrocytes, deoxygenated native RSC, or a deoxygenated sample of RSC after repetitive sickling/unsickling.

The results are interpreted to indicate that the destabilization of the lipid bilayer in sickled cells, expressed by the enhanced flip-flop of PC and the exposure of PS in the outer monolayer, occurs predominantly in those parts of the membrane that are in spicular form.

\section{Introduction}

The phospholipids in the erythrocyte membrane are organized across the bilayer in a nonrandom fashion. Almost all choline containing phospholipids are localized in the outer monolayer,

Received for publication 5 March 1984 and in revised form 24 July 1984.

J. Clin. Invest.

(c) The American Society for Clinical Investigation, Inc.

0021-9738/85/01/0183/08 $\$ 1.00$

Volume 75 , January $1985,183-190$ while the major part of phosphatidylethanolamine (PE) ${ }^{1}$ and all of the phosphatidylserine (PS) reside in the inner layer (1, 2). The asymmetric distribution of phospholipids is not perturbed by the transbilayer movement of the phospholipids, which is common to most natural membranes (2). Although the translocation rate of phosphatidylcholine (PC) over the bilayer is relatively fast (half-time $\left[t_{1}\right]=13-24 \mathrm{~h}$ ) in comparison with the 120-d lifespan of the human erythrocyte (3-6), the asymmetric distribution of PC is maintained throughout.

From model experiments $(7,8)$ as well as from studies on either chemically modified normal erythrocytes $(4,9-13)$ or abnormal erythrocytes $(6,14-16)$, evidence is accumulating that this remarkable arrangement and slow transbilayer movement of the phospholipids are stabilized by the membrane skeleton.

Among the above mentioned abnormal erythrocytes, which are characterized by either a lesion in their membrane skeleton or a defect in intracellular components affecting the structure of this network $(17,18)$, sickled erythrocytes have been studied most extensively in this respect. When these cells are induced to sickle, increased amounts of PE and PS become accessible to phospholipid-localizing reagents $(14,15)$, which is most likely the consequence of enhanced transbilayer mobilities of phospholipids as established for PC (6). These alterations are abolished as soon as the cells are unsickled by reoxygenation, indicating that they are closely related to the sickling process.

In a previous communication, we postulated that the abnormalities in phospholipid organization in the membrane of the deoxygenated reversibly sickled cells (RSC) could be confined to those parts of the membrane that belong to the characteristic spicular protrusions (6). This hypothesis was partly based on the suggestion of Allan and co-workers (19, 20) that during the process of sickling, filaments of polymerized hemoglobin protrude through the skeletal network, thereby breaking its interaction with the membrane bilayer and resulting in the long terminal spicules of the sickled erythrocyte. Therefore, it may be assumed that in those areas of the membrane the phospholipid molecules no longer experience the constraints of the skeleton and an enhanced transbilayer mobility may occur, which ultimately results in an altered distribution of phospholipids across the bilayer.

To test the above hypothesis, we studied some aspects of the phospholipid organization in both isolated free spicules

1. Abbreviations used in this paper: ISC, irreversibly sickled cells; PA, phosphatidic acid; PC, phosphatidylcholine; PE, phosphatidylethanolamine; PS, phosphatidylserine; RSC, reversibly sicklable cells; SM, sphingomyelin. 
and remnant "despiculated" cells that were obtained from RSC, subjected to a series of sickling and unsickling cycles $(19,20)$. The transbilayer mobility of PC was used as a marker for the (in)stability of the lipid bilayer in the remnant despiculated RSC and the results were compared with those from similar experiments involving native RSC and ISC, both under oxygenating and deoxygenating conditions.

Conventional methods could not be applied to the isolated spicules to get information on the organization of their phospholipids. However, the relationship which has been shown to exist between prothrombinase-enhancing activity of a membrane surface and the presence of PS therein (21-23) was used as an alternative to characterize the altered phospholipid organization in the isolated spicules.

The results obtained from both entirely independent types of experiments indicate that the destabilization of the lipid bilayer is indeed confined, for the greater part, to those areas of the membrane which form part of the extremities protruding from the sickled RSC.

\section{Methods}

Chemical materials. Egg PC, egg PE, bovine brain sphingomyelin (SM), and bovine brain PS were obtained from Sigma Chemical Co. (St. Louis, MO), and cholesterol from Merck Co. (Darmstadt, Federal Republic of Germany). Phosphatidic acid (PA) was prepared from egg PC by hydrolysis with phospholipase D. Egg [methyl $\left.-{ }^{14} \mathrm{C}\right] \mathrm{PC}$ was synthesized according to Stoffel (24) using $\left[{ }^{14} \mathrm{C}\right]$ methyliodide from The Radiochemical Centre Ltd. (Amersham, United Kingdom). Glycerol $\left[{ }^{3} \mathrm{H}\right]$ trioleate was also purchased from The Radiochemical Centre Ltd. Penicillin and streptomycin were from Seromed (Berlin, Federal Republic of Germany). Percoll was obtained from Pharmacia Fine Chemicals (Uppsala, Sweden) and Biosolv from Beckman Instruments (Fullerton, CA). PC-specific exchange protein was purified from beef liver according to Kamp and Wirtz (25), while the phospholipase $A_{2}$ from Naja naja, bee venom, and pig pancreas were purified by the methods of Zwaal et al. (1), Shipolini et al. (26), and Nieuwenhuizen et al. (27), respectively. Coagulation Factor Xa, Factor Va, prothrombin, and thrombin were isolated and purified as described by Bevers et al. (28). Chromogenic substrate $H$-D-phenylalanyl-L-pipecolyl-L-argininep-nitroanilide (S2238) was from Kabi Diagnostica (Stockholm, Sweden).

Biological materials. After informed consent, whole blood from homozygous sickle cell patients and healthy individuals was collected in heparinized tubes. The cells were pelleted by centrifugation for 5 min at $2500 \mathrm{~g}$ and after removal of the buffy coat by aspiration, washed twice by suspending them in four volumes of isotonic buffer, pH 7.4, containing $90 \mathrm{mM} \mathrm{KCl}, 45 \mathrm{mM} \mathrm{NaCl}, 44 \mathrm{mM}$ sucrose, 10 $\mathrm{mM}$ glucose, and $10 \mathrm{mM} \mathrm{Tris} / \mathrm{HCl}$; this is referred to as "buffer" throughout.

ISC-fractionation. Subpopulations of sickle cells were obtained using the method of Murphy (29). The bottom fraction (5\% of total) appeared to be highly enriched in ISC $(>60 \%)$ as identified under oxygenated conditions by criteria described by Eaton et al. (30). The remainder of the cells was considered to be the RSC fraction, which were poor in ISC $(<5 \%)$.

Release of spicules. RSC were "despiculated" by repetitive sickling and unsickling of the cells, following the method described by Allan et al. (19). A 33\% suspension of RSC in buffer was gently agitated in a waterbath at $37^{\circ} \mathrm{C}$. To prevent bacterial growth, the incubation mixture contained streptomycin $(0.27 \mathrm{mg} / \mathrm{ml})$ and penicillin $(270 \mathrm{IU} /$ $\mathrm{ml})$. The cell suspension was first exposed to an atmosphere of nitrogen for $1 \mathrm{~h}$, during which the cells gained their sickled shape. They were subsequently reoxygenated by exposure to room air for $30 \mathrm{~min}$. This cycle was repeated twice to complete the despiculation process. When a fourth sickling/unsickling cycle was performed, no additional release of spicules could be detected. The despiculated (remnant) cells were pelleted by centrifugation for $5 \mathrm{~min}$ at $500 \mathrm{~g}$, washed three times, and kept under nitrogen throughout the experiment.

Isolation of spicules. The original supernatant, as well as those obtained after the washings, contained the fragmented cell material. This material was recovered by centrifugation for $10 \mathrm{~min}$ at $31,000 \mathrm{~g}$. The pellet contained the free spicules as well as ghost membranes originating from lysed cells. Since the complete absence of ghost membranes is essential in our studies, the spicules were further isolated on a density gradient $(10 \mathrm{ml}, \rho=1.025-1.1125 \mathrm{~g} / \mathrm{ml})$ which was prepared by centrifugation of a $30 \%$ isotonic Percoll solution for $\mathbf{3 0}$ min at $31,000 \mathrm{~g}$ using a Sorvall SS-34 fixed-angle rotor (DuPont Instruments-Sorvall Biomedical Div., Newtown, CT) (31). A suspension of the spicule-containing fraction was layered on top of the gradient and centrifugation was performed for $10 \mathrm{~min}$ at $31,000 \mathrm{~g}$ using the same rotor.

Phospholipase $A_{2}$ treatment. Washed intact erythrocytes (150 $\mu 1$ packed cells) were suspended in 5 vol of a buffer with the following composition: $90 \mathrm{mM} \mathrm{KCl}, 45 \mathrm{mM} \mathrm{NaCl}, 10 \mathrm{mM} \mathrm{CaCl}, 0.25 \mathrm{mM}$ $\mathrm{MgCl}_{2}, 22 \mathrm{mM}$ sucrose, $10 \mathrm{mM}$ Tris/HCl, $\mathrm{pH} 7.4$, which also contained phospholipases from Naja naja and bee venom, each at a concentration of $40 \mathrm{IU} / \mathrm{ml}$. After incubation at $37^{\circ} \mathrm{C}$ for $1 \mathrm{~h}$, cells were collected by centrifugation and further action of the phospholipases was terminated by resuspending the cells in $0.5 \mathrm{ml}$ buffer containing $100 \mathrm{mM}$ EDTA. The cells were lysed by adding a cold $10 \mathrm{mM}$ EDTA solution saturated with $\mathrm{CO}_{2}$. After $1 \mathrm{~h}$ at $4^{\circ} \mathrm{C}$, the ghost membranes were spun down at $4,500 \mathrm{~g}$ for $30 \mathrm{~min}$ and stored at $-20^{\circ} \mathrm{C}$ until lipid extraction and analysis were performed. The extent of hemolysis was determined at the end of each incubation by comparing the hemoglobin content in the supernatant of each sample to that of a $100 \%$ hemolyzed control.

Lipid analysis. Erythrocyte lipids were extracted using the method of Rose and Oklander (32) and finally dissolved in $2.5 \mathrm{ml} \mathrm{CHCl} /$ $\mathrm{CH}_{3} \mathrm{OH}(2: 1, \mathrm{vol} / \mathrm{vol})$. A sample of $1 \mathrm{ml}$ was used for the fractionation of lipids by two-dimensional thin-layer chromatography described by Broekhuyse (33). The phosphate content of the individual phospholipid spots, visualized by iodine vapor, was measured by the method of Rouser et al. (34). The content of cholesterol recovered from the thinlayer plates was measured according to Zlatkis et al. (35). When radioactivity in the PC and lyso-PC fractions had to be determined, a 1-ml sample of the above lipid extract was separated by one-dimensional thin-layer chromatography using chloroform:methanol:25\% ammonia: water (90:54:5.5:5.5, vol/vol) as developing system. Spots corresponding to $\mathrm{PC}$ and lyso-PC were scraped from the plates and transferred into counting vials. The scintillation medium added was toluene, containing 2,5-diphenyloxazole (5 g/liter), methyl-1,4-bis[2-(5-phenyl-oxazolyl)]benzene $(0.25 \mathrm{~g} /$ liter $)$ and Biosolv $(2 \%, \mathrm{vol} / \mathrm{vol})$. Radioactivity was measured by ${ }^{14} \mathrm{C}$-single channel ratio methods. The ${ }^{3} \mathrm{H} /{ }^{14} \mathrm{C}$-dual label method was used to determine total ${ }^{3} \mathrm{H}$ - and ${ }^{14} \mathrm{C}$-radioactivity in 0.2 $\mathrm{ml}$ of the total lipid extract.

Determination of $\left[{ }^{14} \mathrm{C}\right] P C$ flip-flop in the erythrocyte membrane. Flip-flop of PC was determined by following the transbilayer equilibration of $\left[{ }^{14} \mathrm{C}\right] \mathrm{PC}$, which was previously introduced into the outer monolayer. The procedure used is summarized below; full details are described elsewhere $(5,6)$. Erythrocytes were suspended in buffer containing PC-specific exchange protein and vesicles that were composed of equimolar amounts of cholesterol and phospholipid (97\% egg PC and 3\% egg PA, molar ratios). These vesicles contained trace amounts of egg [methyl- $\left.{ }^{14} \mathrm{C}\right] \mathrm{PC}(91 \mu \mathrm{Ci} / \mathrm{mmol}$ of vesicle $\mathrm{PC})$ and glycerol $\left[{ }^{3} \mathrm{H}\right]$ trioleate $(0.91 \mathrm{mCi} / \mathrm{mmol}$ of vesicle $\mathrm{PC})$, the latter as a nonexchangeable marker. During incubation at $37^{\circ} \mathrm{C}$, the protein replaces part of the native $\mathrm{PC}$ in the outer monolayer of the intact erythrocyte with $\left[{ }^{14} \mathrm{C}\right] \mathrm{PC}$ originating from the vesicles. After $1 \mathrm{~h}$, vesicles and protein were washed away and the residual cells resuspended in buffer. The redistribution of the radioactive PC over the bilayer was measured at timed intervals during a subsequent incubation at $37^{\circ} \mathrm{C}$ for up to 8 h. To discriminate between radioactive $P C$ in both halves of the membrane bilayer, intact cells were incubated with phospholipase $A_{2}$ under nonlytic conditions. The enzyme selectively hydrolyzes only 
those PC molecules situated in the outer monolayer, which were subsequently analyzed as lyso-PC. The rate constant for the transbilayer equilibration of PC $(\mathrm{g})$ was determined from the slope of the straight line, which results when the relative specific radioactivity of the lyso$\mathrm{PC}$, expressed as $\left(\mathrm{SA}_{\mathbf{t}}-\mathrm{SA}_{\infty}\right) /\left(\mathrm{SA}_{\mathbf{0}}-\mathrm{SA}_{\infty}\right)$, is plotted semilogarithmically vs. time of incubation. From the rate constant $(\mathrm{g})$, the half-time $\left(t_{\frac{1}{2}}\right)$ of PC equilibration was calculated as $0.693 / \mathrm{g}$ (5). $\mathrm{SA}_{\mathrm{t}}$ is the specific radioactivity of lyso-PC produced by phospholipase $A_{2}$ treatment of intact cells started at time $t$. $\mathrm{SA}_{\infty}$ is the specific radioactivity of lyso$\mathrm{PC}$ at infinite time of incubation at $37^{\circ} \mathrm{C}$ when complete equilibration would be reached. This value is identical to the specific radioactivity of the entire $\mathrm{PC}$ pool of the intact cell. $\mathrm{SA}_{0}$ is the specific radioactivity of lyso-PC at zero time. Before their use in these calculations, the analytical data were corrected for contamination of the erythrocytes with the $\left[{ }^{14} \mathrm{C}\right] \mathrm{PC} /$ cholesterol vesicles, making use of the nonexchangeable marker. Contamination never exceeded $2 \%$ of the total erythrocyte phospholipids.

Determination of procoagulant activity by thrombin formation. The capacity of the spicules, various erythrocytes, cell fractions, and phospholipid vesicles to enhance the rate of thrombin formation was determined in an assay using highly purified coagulation factors and a chromogenic substrate. Full details and background of this procedure are published by Bevers et al. (28). All material to be tested was incubated at concentrations corresponding to $1 \mu \mathrm{M}$ total phospholipid at $37^{\circ} \mathrm{C}$, under continuous stirring, with highly purified components of the prothrombinase complex at final concentrations of $4 \mu \mathrm{M}$ prothrombin/Factor II), $0.5 \mathrm{nM}$ Factor Xa, $1.0 \mathrm{nM}$ Factor Va, and 3 $\mathrm{mM} \mathrm{CaCl}_{2}$ in an isotonic buffer, $\mathrm{pH}$ 7.9. After $1 \mathrm{~min}$, a sample of 25 $\mu \mathrm{l}$ was taken and the conversion of prothrombin to thrombin terminated by adding this aliquot to $1 \mathrm{ml}$ of a buffer containing $50 \mathrm{mM}$ Tris, 120 $\mathrm{mM} \mathrm{NaCl}, 2 \mathrm{mM}$ EDTA, and $0.249 \mathrm{mM}$ S2238 as chromogenic substrate. The amount of thrombin formed was determined from the change in absorbance at $\mathbf{4 0 5} \mathbf{n m}$ using a calibration curve recorded with known concentrations of active-site titrated thrombin.

\section{Results}

Production and isolation of free spicules and remnant despiculated cells. Sickle cells that had been subjected to three deoxygenation-reoxygenation cycles exhibited a morphology as shown in Fig. $1 a$ when incubated under nitrogen. In general, they had a deformed cell body with short stubby protrusions, but were devoid of the long characteristic spicules that are found when native sickle cells are deoxygenated for
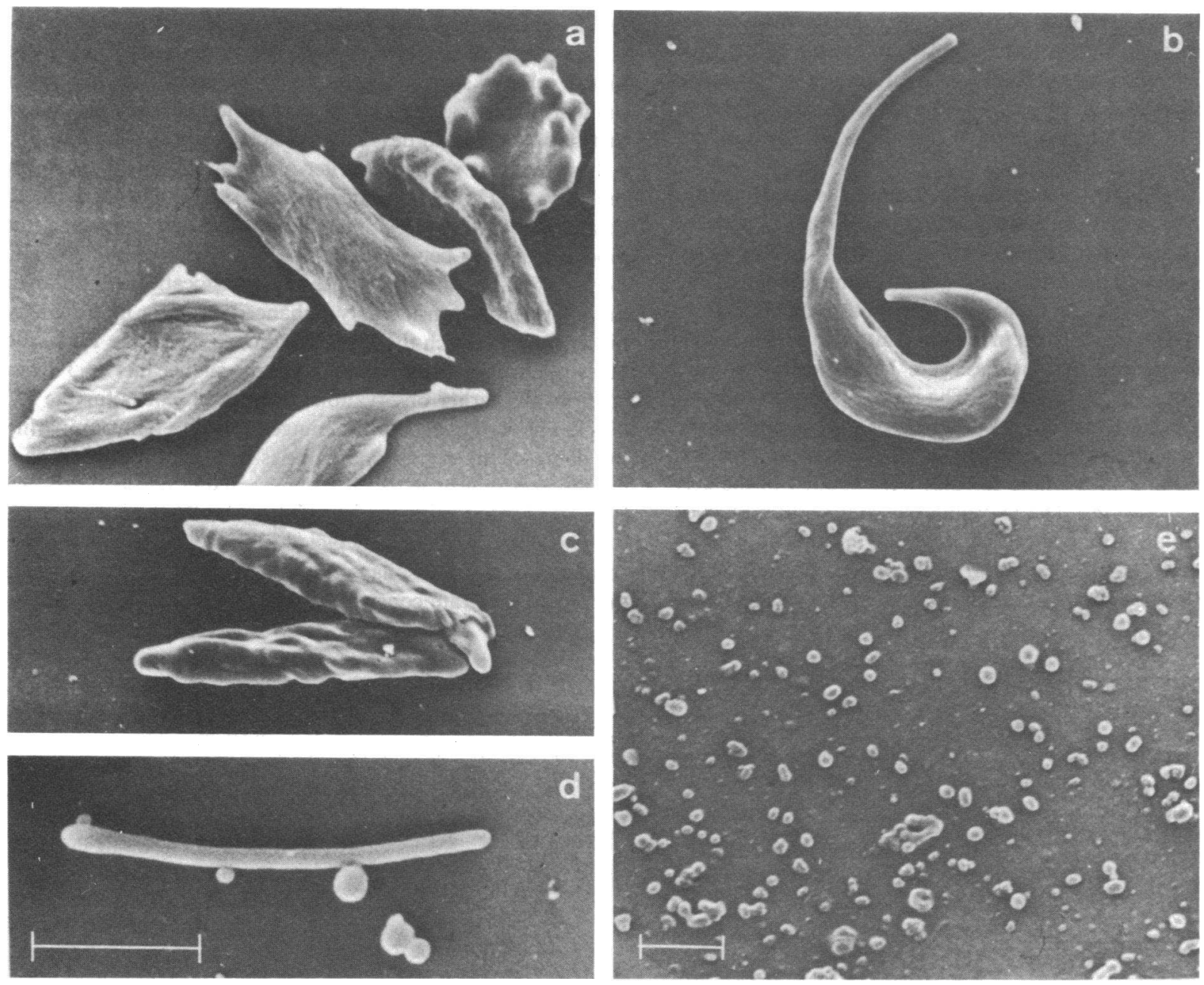

Figure 1. Scanning electron micrographs of various types of sickle cells and released membrane structures. Erythrocytes and released membrane structures were incubated in buffer, sampled, and fixed in $10 \mathrm{vol}$ of $0.4 \%$ formaldehyde in isotonic buffer for 30 min at room temperature. The fixed cells were subsequently incubated in $1 \%$ osmium tetraoxide dissolved in buffer for 30 min, dehydrated with graded ethanol, and finally suspended in isopropanol. Erythrocytes and released membrane material were air-dried on glass coverslips and covered with a thin layer of coal and gold. The figure shows $(a)$ deoxygenated despiculated RSC, $(b)$ deoxygenated native RSC, $(c)$ oxygenated ISC, $(d)$ spicules, and $(e)$ purified microvesicles. Bars indicated represent a length of $5 \mu \mathrm{M}$. Magnification factors of $a, b$, and $c$ are identical to that of $e$. 
the first time (Fig. $1 b$ ). Although the morphology of many of the deoxygenated, despiculated cells (Fig. $1 a$ ) resembled that of ISC (Fig. $1 \mathrm{c}$ ), remnant cells, in contrast to ISC, revert to their original discoid shape upon reoxygenation. These repeated sickling cycles did not lead to the formation of permanently deformed cells as reported by others $(36,37)$. However, the sickle/unsickle cycles did induce the release of membrane material in the form of rodlike structures and microspheres (Fig. $1 d$ ). In agreement with others $(19,20,36-39)$, we consider this membrane material to be representative of the terminal spikes on the sickled cell (Fig. $1 b, d$ ), which were shed from the cell body after reoxygenation. Exposure to room air for longer periods induced further fragmentation of these free spicules into microvesicies (Fig. $1 e$ ) due to depolymerization of the enclosed hemoglobin $\mathrm{S}$ gel. These microvesicles are also referred to as "spicules."

Release of cell material was virtually complete after the third sickle/unsickle cycle. Remnant cells with short, stubby protrusions were pelleted by low-speed centrifugation $(5 \mathrm{~min}$ $\times 500 \mathrm{~g}$ ) and washed twice. The low-speed supernatant contained, besides spicules, ghost membranes, which could be easily removed by Percoll gradient centrifugation as described in Methods. The majority of the spicules, collected as microvesicles, appeared in a sharp band near the bottom of the tube ( $\rho=1.080 \mathrm{~g} / \mathrm{ml}$ ), whereas the ghost membranes remained on top of the gradient $(\rho=1.025 \mathrm{~g} / \mathrm{ml})$. The morphology of a representative sample of isolated microvesicles is shown in Fig. $1 e$.

Protein and lipid composition. Fig. 2 shows the densitometric scans of the protein profiles after separation by sodium dodecyl sulfate-polyacrylamide gel electrophoresis from native sickle cell membranes $(A)$ and the total protein complement of the isolated spicules $(B)$. As in normal erythrocytes, bands 1, 2, and 3 form the major protein components of the sickle cell membrane, whereas the spicules were largely devoid of the protein bands 1 and 2 (spectrin). The ratio of spectrin to band 3 in the spicules is no more than $10 \%$ of that in the native cells. The major protein component of the spicule fraction was hemoglobin, since whole spicules were applied to the gels in these fractionations. The phospholipid composition of spicules was similar to that of the native sickle erythrocyte (Table I). Cholesterol/phospholipid ratio (mole/mole) in the spicules $(0.85 \pm 0.03)$ was also very similar to that in the whole sickle cells $(0.82 \pm 0.04)$.

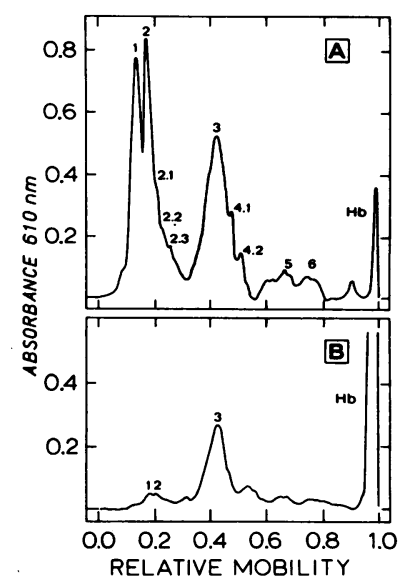

Figure 2. Densitometric scans of sodium dodecyl sulfate-polyacrylamide gels of proteins from $(A)$ sickle cell membranes and (B) isolated spicules. Sickle cells were first converted into ghosts according to Dodge et al. (48). The proteins were separated on 7\% polyacrylamide slab gels following the procedure of Laemmli (49).
Table I. Phospholipid Composition of Intact Sickle Cells and Released Spicules

\begin{tabular}{lll}
\hline & \multicolumn{2}{c}{ Molar ratios of phospholipids } \\
\cline { 2 - 3 } Phospholipid & Sickle cells & Spicules \\
\hline & $\%$ & $\%$ \\
SM & $25.5 \pm 1.8$ & $25.9 \pm 0.6$ \\
PC & $30.2 \pm 1.6$ & $31.4 \pm 1.5$ \\
PE & $26.8 \pm 1.4$ & $25.3 \pm 0.5$ \\
PS & $14.9 \pm 1.6$ & $14.1 \pm 0.9$ \\
PA & $2.0 \pm 1.1$ & $3.2 \pm 0.7$ \\
\hline
\end{tabular}

Data represent means \pm SD from duplicate analyses of two different samples.

Transbilayer mobility of PC. Flip-flop of PC was studied by following the transbilayer equilibration of $\left[{ }^{14} \mathrm{C}\right] \mathrm{PC}$, previously introduced into the outer monolayer of oxygenated RSC and despiculated sickle cells. The equilibration of the radioactive PC was determined by measuring the specific radioactivity of PC in the outer layer converted into lyso-PC by phospholipase $A_{2}$ treatment of the intact cells. The time-dependent change in the relative specific radioactivity of the PC in the outer monolayer of oxygenated and deoxygenated RSC, as well as that of deoxygenated despiculated sickle cells, is shown in Fig. 3. In agreement with our earlier observations (6), transbilayer mobility of PC in oxygenated discoid sickle cells appeared to be a slow process; the corresponding half-time value for this process can vary between 15 and $20 \mathrm{~h}$. However, when RSC were sickled for the first time, the translocation of PC over the bilayer was considerably enhanced. This is indicated by higher rates at which the specific radioactivity of the PC in the outer monolayer decreased. The results shown in Fig. 3 again confirm our earlier observations. Half-time values for the PC flip-flop in deoxygenated RSC range from 3 to $6 \mathrm{~h}$. Comparing the slopes of the corresponding lines in Fig. 3, it appears that the flip-flop rate of PC in the deoxygenated despiculated cell is similar to that in the oxygenated native RSC.

The slope of the lines depicted in Fig. 3 represents the rate constants of the transbilayer equilibration of PC in the three samples. These rate constants are shown in Fig. 4, for deoxy-

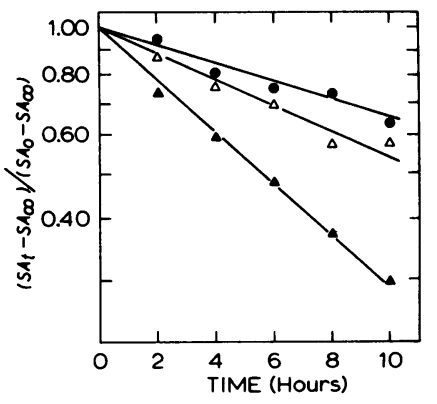

Figure 3. Transbilayer mobility of PC in various types of RSC. Transbilayer movement of $\mathrm{PC}$ was determined by introducing $\left[{ }^{14} \mathrm{C}\right] \mathrm{PC}$ molecules into the outer monolayer and following the equilibration of the radioactively labeled molecules over both halves of the bilayer. The amount of the $\left[{ }^{14} \mathrm{C}\right] \mathrm{PC}$ present in the outer monolayer was determined as lyso-PC

after a nonlytic treatment of the cells with phospholipase $A_{2}$. The relative specific radioactivity $(\mathrm{SA})$ of this lyso-PC calculated as $\left(\mathrm{SA}_{\mathbf{t}}\right.$ $\left.\mathbf{S A}_{\alpha}\right) /\left(\mathbf{S A}_{0}-\mathbf{S A}_{\alpha}\right)$ is plotted semilogarithmically vs. time for oxygenated RSC (๑), deoxygenated RSC ( $\Delta)$, and deoxygenated despiculated $\operatorname{RSC}(\Delta)$. 


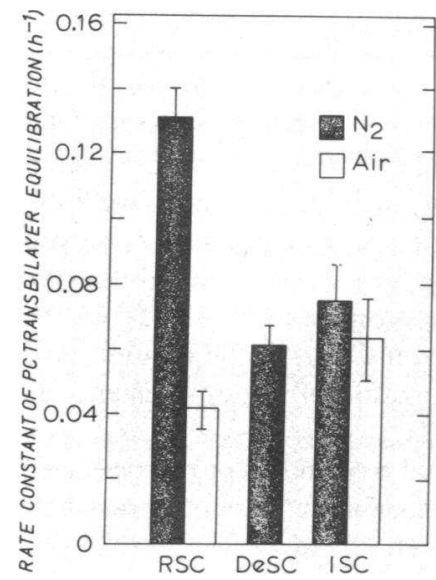

and oxygenated RSC, deoxygenated despiculated RSC, and deoxy- and oxygenated ISC, respectively. A difference can hardly be observed in the rate constant for PC flip-flop in ISC when incubated under either deoxy- and oxygenated conditions. Furthermore, the rate constant in both of these cases is considerably lower than that for PC flip-flop in deoxygenated native RSC and closely resembles that for the process in deoxygenated despiculated RSC (Fig. 4). In this context, it is worth drawing attention to the fact that the morphology of the ISC is quite similar to that of the deoxygenated despiculated RSC in that both cell types lack the long terminal spicules characteristic for deoxygenated native RSC (compare Figs. 1 $a, b$, and $c$ ).

The above method cannot be applied to determine the rate of PC flip-flop in the released spicules because these spicules hemolyze extensively when incubated with phospholipase $A_{2}$. Even a tenfold lower bee venom phospholipase $A_{2}$ concentration than that used for intact erythrocytes gives rise to $>30 \%$ hemolysis of the spicules. Remarkably, similar hemolysis occurred with porcine pancreas phospholipase $A_{2}$. The latter phospholipase is unable to hydrolyze the phospholipids in intact erythrocytes $(1,40)$.

Prothrombinase-enhancing activity. The observation that spicules lyse in the presence of phospholipase $A_{2}$ did not allow for its use to assess the transbilayer distribution of glycerophospholipids in these spicules. However, it has been demonstrated that the presence of PS in a lipid surface is an important prerequisite for the effective formation of the prothrombinase complex $(22,41)$. Hence, an in vitro incubation system involving highly purified clotting Factor $\mathrm{Xa}$, Factor $\mathrm{Va}$, and prothrombin in the presence of $\mathrm{Ca}^{2+}$ has been developed and has been shown to be a reliable marker for the presence of PS in the exterior surface of natural and artificial membrane systems $(22,28,41)$. The amount of thrombin formed, as determined by a chromogenic substrate, can therefore be related to the amount of PS present in the membrane surface $(22,41)$. The fact that the formation of thrombin indeed specifically depends on the presence of PS is further substantiated by the experiments depicted in Fig. 5. Sonicated phospholipid/cholesterol (1:1, mole/mole) vesicles containing PC, $\mathrm{SM}$, and $\mathrm{PE}$ at molar ratios corresponding to those in the spicules (Table I) did not promote the formation of thrombin to any appreciable extent. However, when the phospholipid fraction of these vesicles was supplemented with increasing quantities of PS, increasing rates of thrombin formation were

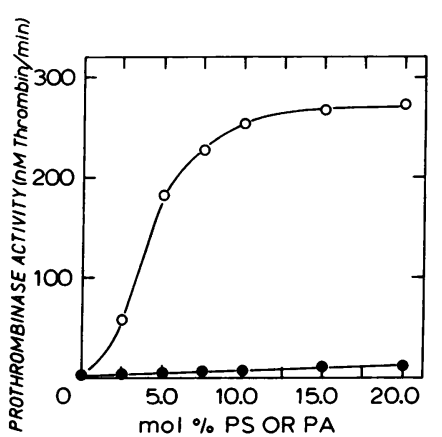

Figure 5. Prothrombinase activity of sonicated phospholipid/cholesterol (1:1, mole/ mole) vesicles containing PC, $\mathrm{SM}$, and $\mathrm{PE}$ at molar ratios of $38: 32: 30$, respectively, and increasing concentrations of either PS (0) or PA ( $\bullet)$. Concentrations of PS or PA are given as mole percent of total phospholipid. In all cases, the vesicle concentration used in the assay system corresponded to 1 $\mu \mathrm{M}$ of total phospholipid. For further details, see Methods.

observed. The rate of thrombin formation reached a plateau value of $\sim 270 \mathrm{nM} / \mathrm{min}$ at 14 mole percent PS. Under the conditions used, this procoagulant activity of PS could not be mimicked by another negatively charged phospholipid such as PA. Even when the latter phospholipid was present at a concentration as high as $20 \mathrm{~mol}$ percent, the rate of thrombin formation was as low as $10 \mathrm{nM} / \mathrm{min}$ (Fig. 5).

Normal erythrocytes, native RSC (both under oxygenating and deoxygenating conditions), RSC repeatedly subjected to the sickling/unsickling procedure, and the isolated spicules released from these cells were used as lipid source in the above assay system. The results of these experiments, which were carried out at a concentration of $1 \mu \mathrm{M}$ of total membrane phospholipid, are summarized in Table II. All of the intact erythrocytes, either normal cells, oxygenated or deoxygenated RSC, induced thrombin formation at a rate as low as 2-3 $\mathrm{nM} / \mathrm{min}$. Even a suspension of RSC subjected to repeated sickling/unsickling and still containing the released spicules displayed this low degree of thrombin-forming activity. Normal erythrocytes, RSC, or isolated spicules, each of them disrupted by sonication, promoted the formation of thrombin at rates ranging from 260 to $270 \mathrm{nM} / \mathrm{min}$ (Table II); these rates are comparable with those recorded for the artificial lipid vesicles containing PS at concentrations of 12 mole percent or more (Fig. 5). Spicules, used at the same total phospholipid concentration of $1 \mu \mathrm{M}$, induced a thrombin formation at a rate of $66 \mathrm{nM} / \mathrm{min}$ (Table II).

Table II. Catalytic Activity of Sickle Cell Membrane Preparations in the Formation of Thrombin

\begin{tabular}{lcl}
\hline & \multicolumn{2}{c}{$\begin{array}{l}\text { Rate of thrombin formation } \\
(n M / m i n \pm S D)\end{array}$} \\
\cline { 2 - 3 } & Intact & Sonicated \\
\hline Normal RBC & $3.0 \pm 0.2$ & $263.7 \pm 17.8$ \\
Oxygenated RSC & $2.1 \pm 0.8$ & $272.6 \pm 15.5$ \\
Deoxygenated RSC & $2.9 \pm 0.9$ & - \\
$\begin{array}{l}\text { Deoxygenated, Reoxygenated } \\
\quad \text { RSC }\end{array}$ & & - \\
Spicules§ & $2.6 \pm 1.0$ & - \\
& $65.8 \pm 3.1$ & $273.1 \pm 13.6$
\end{tabular}

* RSC subjected to repeated sickling/unsickling; the suspension contained the released spicules which account for only $2-3 \%$ of the total membrane lipid material.

$\S$ Mostly in the form of microvesicles (see text). 


\section{Discussion}

Previous studies have shown that the process of sickling of RSC is accompanied by changes in the organization of the lipid bilayer $(6,14,15)$. It has been suggested that these changes may take place predominantly in those parts of the membrane that are in spicular form rather than in the overall surface of the membrane of the sickled RSC (6). This view is supported by the observation of Allan et al. (19) that the spicules that are released from RSCs by repetitive sickling/ unsickling are essentially devoid of the skeletal proteins. Therefore, the sickling/unsickling procedure used by Allan et al. (19) provides a unique opportunity to study both the free spicules and remnant despiculated RSC separately.

Remnant cells are easily isolated by low-speed centrifugation. The free spicules, present in the low-speed supernatant, are contaminated with ghost membranes, which can be removed completely by centrifugation on a Percoll density gradient. This procedure produces a homogeneous preparation within a relatively short period of time compared with other methods used to isolate microvesicles $(42,43)$. In agreement with the observations of others $(19,38,39)$, the spicules thus isolated as microvesicles were largely deficient in spectrin (Fig. 2), the major protein of the membrane skeleton, whereas the cholesterol/phospholipid ratio as well as the relative quantity of individual phospholipids were very similar to that in the original cell.

In view of the hypothesis that the enhanced transbilayer movement of PC observed in sickled RSC occurs only in their spicules, it was expected that this acceleration would be absent or less obvious in the remnant despiculated cells. Our experimental results show that this is indeed the case. The dramatic increase in transbilayer mobility of PC which takes place upon deoxygenation of native RSC is no longer observed in the deoxygenated remnant cells (Figs. 3 and 4). Interestingly, the rate of transbilayer movement of $\mathrm{PC}$ in the deoxygenated, remnant despiculated RSC appeared to be comparable with that in ISC, the latter incubated either under oxygenating or deoxygenating conditions. The deoxygenated remnant RSC, which still show marked morphological deformation, resemble the permanently deformed ISC in that they lack spicules. Therefore, this supports the hypothesis that the considerably accelerated transbilayer movement of PC observed in deoxygenated native RSC occurs predominantly in these protrusions. Furthermore, it may be suggested that the existence of a permanently perturbed membrane skeleton in ISC accounts for the slightly enhanced transbilayer movement of PC that is observed even when these cells are oxygenated (Fig. 4).

Direct evidence for our hypothesis would be provided by demonstrating that the PC molecules in the bilayer of the isolated free spicules experience high flip-flop rates. Unfortunately, such studies could not be performed since these spicules experience considerable lysis when incubated with phospholipase $A_{2}$, a treatment which is indispensable in the technique we use for the determination of PC flip-flop rates. In previous studies, we used the protein-mediated exchangeability of PC to detect its enhanced transbilayer mobility in the membrane of abnormal erythrocytes $(4,6)$. The procedure for despiculation and subsequent isolation of the free spicules in a pure form, however, finally yields $<1 \%$ of the total membrane material, which is much too low for the application of this alternative method.
Another feature of the destabilized membrane bilayer of the sickled RSC appeared to be an enhanced accessibility of the amino-phospholipids for phospholipase $A_{2}$ (15). As already mentioned above, this enzyme causes considerable lysis of the free spicules and therefore, could not be used to determine phospholipid sidedness in their membrane. Thus, we took advantage of the fact that the presence of negatively charged phospholipids on a membrane surface is essential for the formation of the prothrombinase complex $(22,41)$. From the results shown in Fig. 5, it is obvious that, in the chromogenic substrate assay we used, the formation of thrombin is entirely dependent on the presence of PS.

Intact normal erythrocytes and oxygenated or deoxygenated RSC did not give rise to the formation of any appreciable amounts of thrombin when incubated at concentrations corresponding to $1 \mu \mathrm{M}$ of total phospholipid (Table II). Disruption of those cells by sonication, thereby exposing the PS in their membranes to the assay medium, induced the formation of thrombin at rates (Table II) which are similar to those induced by the artificial lipid vesicles containing $>12$ mole percent of PS. The same level of activity was observed with sonicated spicules. However, unlike the intact native erythrocytes, intact free spicules also enhanced the rate of thrombin formation, indicating the presence of PS in the outer half of their membranes.

Although it may be tempting to use the calibration curve shown in Fig. 5 to determine the concentration of PS present at the outer surface of the spicular membrane, it should be realized that this curve has been recorded using artificial lipid vesicles composed of pure lipids. Therefore, the rate of thrombin formation of $66 \mathrm{nM} / \mathrm{min}$ determined for the free spicules may not necessarily mean that the phospholipid fraction in the outer layer of the spicular membrane contains 2.5 mole percent of PS. It should be noted that at a complete random distribution of PS over both halves of the bilayer, this value would be $14 \%$ (compare Table I). However, the relationship between the amount of PS present at the outer surface of a membrane and its procoagulant activity is very complex (44), and therefore, it may not be possible to directly compare the activity of the free spicules, still containing many of the other constituents of the RSC membrane, with that of a membrane system composed of pure lipids only. Nonetheless, our experimental results show that a significant fraction of PS is present in the outer half of the membrane of the spicule. In contrast to the free spicules, deoxygenated RSC and even the RSC subjected to repetitive sickling/unsickling, did not show any appreciable procoagulant activity when incubated at the same total phospholipid concentration (Table II). These observations support our hypothesis that the abnormality in the phospholipid organization in the sickled RSC is confined to those areas of the membrane which are in spicular form. Since $2-3 \%$ of the total membrane area is in spicular form, one cannot expect the total procoagulant activity of the above RSC fractions to be more than one-thirtieth of that observed in case of the free spicules. This is indeed what we observed (Table II). This interpretation may also explain the apparent discrepancy concerning the procoagulant activity of the deoxygenated RSC in the present study as compared with a previous one (45) using the Russell's viper venom assay which had been performed at total phospholipid concentrations of at least two orders of magnitude higher than that used in the chromogenic substrate assay. 
The spicules released from sickle cells have been identified in the plasma of patients with sickle cell disease $(19,39)$, suggesting that the events we have characterized in vitro may have significance in vivo. In particular, the hypercoagulable state observed in sickle cell disease (45) may be, in part, secondary to the procoagulant activity of these spicules. Furthermore, it is possible that these lipid vesicles block the monocyte/macrophage system and contribute to the immune deficiency associated with this disease (46). Recently, Tanaka and Schroit (47) have demonstrated that liposomes containing PS inhibit monocyte recognition of PS-loaded erythrocytes. It is possible that the spicules that circulate in the plasma of sickle cell patients block the monocyte/macrophage system. Under normal conditions, one might expect that these lipid/ hemoglobin structures would be rapidly removed from the circulation. Therefore, we speculate that spicule formation and their release from sickled cells may contribute to the clinical manifestations associated with this disease.

The absence of an enhanced PC flip-flop in the deoxygenated, remnant despiculated RSC and the increased procoagulant activity of the released spicules provides evidence that the destabilization of the lipid bilayer predominantly occurs in the protrusions of the sickled cell. In fact, it also supports our earlier suggestions (6) that the abnormalities in the organization of amino-phospholipids (particularly PS), which we have previously reported to exist in sickled cells $(14,15)$, may represent enhanced accessibility to nonpenetrating probes as a consequence of changes in the transversal dynamics rather than a static redistribution of these phospholipids across the bilayer of the entire membrane in these cells. Since the destabilization of the membrane bilayer of the spicules may be caused by a break in the interaction between the cytoplasmic monolayer and the membrane skeletal network, our results are consistent with the idea that the coupling between this skeleton and the bilayer is essential for a stable asymmetric phospholipid organization.

\section{Acknowledgments}

For the supply of homozygous sickle cell blood, we are most grateful to Dr. L. W. Statius van Eps (Slotervaart Hospital, Amsterdam, The Netherlands) and Dr. H. C. van Prooyen (Academic Hospital, Utrecht, The Netherlands) as well as to the clinical staff of the Northern California Sickle Cell Center and particularly to K. Kleman. We are also indebted to Mrs. M. van Linde and Dr. F. A. Kuypers for their contributions in the purification of the PC-specific phospholipid exchange protein, and to Dr. W. Berendsen for carrying out the scanning electron microscopy. The authors are also grateful to Ms. J. Hardesty and Ms. R. Obbink for an excellent job in typing this manuscript.

This work was supported by National Institutes of Health grants HL-20985, HL-27059, and RR-05457, and North Atlantic Treaty Organization Travel grant 255/81. In addition, the present investigations were carried out under the auspices of The Netherlands Foundation for Chemical Research (S.O.N.) and with financial support from The Netherlands Organization for the Advancement of Pure Research (Z.W.O.).

\section{References}

1. Zwaal, R. F. A., B. Roelofsen, P. Comfurius, and L. L. M. van Deenen. 1975. Organization of phospholipids in human red cell membranes as detected by the action of various purified phospholipases. Biochim. Biophys. Acta. 406:83-96.
2. Op den Kamp, J. A. F. 1979. Lipid asymmetry in membranes. Annu. Rev. Biochem. 48:47-71.

3. van Meer, G., B. J. H. M. Poorthuis, K. W. A. Wirtz, J. A. F. Op den Kamp, and L. L. M. van Deenen. 1980. Transbilayer distribution and mobility of phosphatidylcholine in intact erythrocyte membranes. A study with phosphatidyl exchange protein. Eur. J. Biochem. 103:283288.

4. Franck, P. F. H., B. Roelofsen, and J. A. F. Op den Kamp. 1982. Complete exchange of phosphatidylcholine from intact erythrocytes after protein crosslinking. Biochim. Biophys. Acta. 687:105-108.

5. van Meer, G., and J. A. F. Op den Kamp. 1982. Transbilayer movement of various phosphatidylcholine species in intact human erythrocytes. J. Cell. Biochem. 19:193-204.

6. Franck, P. F. H., D. T.-Y. Chiu, J. A. F. Op den Kamp, B. Lubin, L. L. M. van Deenen, and B. Roelofsen. 1983. Accelerated transbilayer movement of phosphatidylcholine in sickled erythrocytes. A reversible process. J. Biol. Chem. 258:8435-8442.

7. Mombers, C., A. J. Verkleij, J. de Gier, and L. L. M. van Deenen. 1979. The interaction of spectrin/actin and synthetic phospholipids. Biochim. Biophys. Acta. 551:271-281.

8. Sato, S. B., and S. I. Ohnishi. 1983. Interaction of peripheral protein of erythrocyte membrane, band 4.1 , with phosphatidylserine containing liposomes and erythrocyte inside-out vesicles. Eur. J. Biochem. 130:19-25.

9. Haest, C. W. M., G. Plasa, D. Kamp, and B. Deuticke. 1978. Spectrin as a stabilizer of the phospholipid asymmetry in the human erythrocyte membrane. Biochim. Biophys. Acta. 509:21-32.

10. Mohandas, N., J. Wyatt, S. F. Mel, E. Rossi, and S. B. Shohet. 1982. Lipid translocation across the human erythrocyte membrane. Regulatory factors. J. Biol. Chem. 257:6537-6543.

11. Williamson, P., J. Bateman, K. Kozarsky, K. Mattocks, N. Hermanowicz, H. R. Choe, and R. A. Schlegel. 1982. Involvement of spectrin in the maintenance of phase state asymmetry in the erythrocyte membrane. Cell. 30:725-732.

12. Haest, C. W. M. 1982. Interactions between membrane skeleton proteins and the intrinsic domain of the erythrocyte membrane. Biochim. Biophys. Acta. 694:331-352.

13. Bergmann, W. L., V. Dressler, C. W. M. Haest, and B. Deuticke. 1984. Cross-linking of SH-groups in the erythrocyte membrane enhances transbilayer reorientation of phospholipids. Evidence for a limited access of phospholipids to the reorientation sites. Biochim. Biophys. Acta. 769:390-398.

14. Chiu, D., B. Lubin, and S. B. Shohet. 1979. Erythrocyte membrane lipid reorganization during the sickling process. $B r . J$. Haematol. 41:233-234.

15. Lubin, B., D. Chiu, B. Bastacky, B. Roelofsen, and L. L. M. van Deenen. 1981. Abnormalities in membrane phospholipid organization in sickled erythrocytes. J. Clin. Invest. 67:1643-1649.

16. Lubin, B., D. Chiu, R. S. Schwartz, B. Cooper, K. John, L. Wolf, and S. E. Lux. 1983. Abnormal membrane phospholipid organization in spectrin deficient human red cells. Blood. 62(Suppl.):34a. (Abstr.)

17. Lux, S. E. 1979. Spectrin-actin membrane skeleton of normal and abnormal red blood cells. Semin. Hematol. 16:21-51.

18. Palek, J., and S. E. Lux. 1983. Red cell membrane skeletal defects in hereditary and acquired hemolytic anemias. Semin. Hematol. 20:189-224.

19. Allan, D., A. R. Limbrick, P. Thomas, and M. P. Westerman. 1982. Release of spectrin free spicules on reoxygenation of sickled erythrocytes. Nature (Lond.). 295:612-613.

20. Westerman, M. P., and D. Allan. 1983. Effects of valinomycin, A23187 and repetitive sickling on irreversible sickle cell formation. $\mathrm{Br}$. J. Haematol. 53:399-409.

21. Zwaal, R. F. A., P. Comfurius, and L. L. M. van Deenen. 1977. Membrane asymmetry and blood coagulation. Nature (Lond.). 268:358-360.

22. Zwaal, R. F. A., and E. M. Bevers. 1983. Platelet phospholipid asymmetry and its significance in hemostasis. In Subcellular Biochem- 
istry. D. B. Roodyn, editor. Plenum Press Corp., New York. 9:299334.

23. Jackson, C. M., and Y. Nemerson. 1980. Blood coagulation. Annu. Rev. Biochem. 49:765-811.

24. Stoffel. W. 1975. Chemical synthesis of choline labeled lecithins and sphingomyelin. Methods Enzymol. 35:533-541.

25. Kamp, H. H., and K. W. A. Wirtz. 1974. Phosphatidylcholine exchange protein from beef liver. Methods Enzymol. 32:140-146.

26. Shipolini, R. A., G. L. Callewaert, R. C. Cottrell, S. Doonan, C. A. Vernon, and B. E. C. Banks. 1971. Phospholipase A from bee venom. Eur. J. Biochem. 20:459-468.

27. Nieuwenhuizen, W., H. Kunze, and G. H. de Haas. 1974. Phospholipase $\mathrm{A}_{2}$ (phosphatidate acylhydrolase, E.C. 3.1.1.4) from porcine pancreas. Methods Enzymol. 32B:147-154.

28. Bevers, E. M., P. Comfurius, J. L. M. L. van Rijn, H. C. Hemker, and R. F. A. Zwaal. 1982. Generation of prothrombinconverting activity and the exposure of phosphatidylserine at the outer surface of platelets. Eur. J. Biochem. 122:429-436.

29. Murphy, J. R. 1973. Influence of temperature and method of centrifugation on the separation of erythrocytes. J. Lab. Clin. Med. 82:334-341.

30. Eaton, J. W., H. S. Jacob, and J. G. White. 1979. Membrane abnormalities of irreversibly sickled cells. Semin. Hematol. 16:52-64.

31. Pharmacia Fine Chemicals. Methodology and Applications of Density Marker Beads for Calibration of Gradients of Percoll. Pharmacia Fine Chemicals, Uppsala, Sweden.

32. Rose, H. G., and M. Oklander. 1965. Improved procedure for the extraction of lipids from human erythrocytes. J. Lipid Res. 6:428431.

33. Broekhuyse, R. M. 1969. Quantitative two-dimensional thinlayer chromatography of blood phospholipids. Clin. Chim. Acta. 23:457461.

34. Rouser, G., S. Fleischer, and A. Yamamoto. 1970. Twodimensional thin-layer chromatographic separation of polar lipids and determination of phospholipids by phosphorus analysis of spots. Lipids. 5:494-496.

35. Zlatkis, A., B. Zak, and A. J. Boyle. 1953. A new method for the direct determination of serum cholesterol. J. Lab. Clin. Med. 41:486-492.

36. Padilla, F., P. A. Bromberg, and W. N. Jensen. 1973. The sickle-unsickle cycle: a cause of cell fragmentation leading to permanently deformed cells. Blood. 41:653-660.

37. Jensen, M., S. B. Shohet, and D. G. Nathan. 1973. The role of red cell energy metabolism in the generation of irreversibly sickled cells in vitro. Blood. 42:835-842.

38. Dumaswala, U., D. J. Bryan, and T. J. Greenwalt. 1982. Studies of the mechanism of membrane changes in sickle cell anaemia. Blood. 60(Suppl. 1):45a. (Abstr.)

39. Chilcote, R. R., B. Jones, and C. Dampier. 1982. Membrane vesiculation in $\mathrm{Hb}$ SS sickle cell anaemia. Blood. 60(Suppl. 1):44a. (Abstr.)

40. Demel, R. A., W. S. M. Geurts van Kessel, R. F. A. Zwaal, B. Roelofsen, and L. L. M. van Deenen. 1975. Relation between various phospholipase actions on human red cell membranes and the interfacial phospholipid pressure in monolayers. Biochim. Biophys. Acta. 406:97107.

41. Bevers, E. M., P. Comfurius, and R. F. A. Zwaal. 1982. The nature of binding site for prothrombinase at the platelet surface as revealed by lipolytic enzymes. Eur. J. Biochem. 122:81-85.

42. Lutz, H. H., S. C. Liu, and J. Palek. 1977. Release of spectrin free vesicles from human erythrocytes during ATP depletion. Characterization of spectrin free vesicles. J. Cell Biol. 73:548-560.

43. Weitz, N., O. J. Bjerrum, P. Ott, and U. Brodbeck. 1982. Quantitative composition and characterization of the proteins in membrane vesicles released from erythrocytes by dimyristoyl phosphatidylcholine. A membrane system without cytoskeleton. J. Cell. Biochem. 19:179-191.

44. van Rijn, J. L. M., J. Rosing, G. van Dieijen, E. M. Bevers, R. F. A. Zwaal, and H. C. Hemker. 1983. The interaction between blood platelets and blood coagulation factors. Arzneim. Forsch. 33: 1365-1369.

45. Richardson, S. G. N., K. B. Mathew, J. Stuart, A. M. Geddes, and R. M. Wilcox. 1979. Serial changes in coagulation and viscosity during sickle cell crisis. Br. J. Haematol. 41:95-103.

46. Barret-Connor, E. 1971. Bacterial infection and sickle cell anemia. Medicine (Baltimore). 50:97-112.

47. Tanaka, Y., and A. J. Schroit. 1983. Insertion of fluorescent phosphatidylserine into the plasma membrane of red blood cells. $J$. Biol. Chem. 258:11335-11343.

48. Dodge, C. T., C. D. Mitchell, and D. Hanahan. 1963. The preparation and chemical characteristics of hemoglobin free ghosts of human erythrocytes. Arch. Biochem. Biophys. 100:119-130.

49. Laemmli, U. K. 1970. Cleavage of structural proteins during the assembly of the head of bacteriophage $T_{4}$. Nature (Lond.). 227:680685 . 